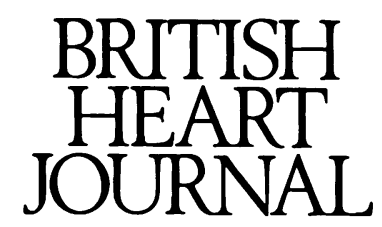

Editorial

\title{
Investigation in general practice of patients with suspected heart failure
}

\author{
How should the essential echocardiographic service be delivered?
}

Heart failure is a life threatening disorder that affects between $0.4 \%$ and $2 \%$ of the general population and up to $10 \%$ of elderly subjects in Europe and North America. ${ }^{1-3}$ Annual mortality exceeds $60 \%$ in severe cases, ${ }^{4}$ and the five year mortality approaches $50 \%$ in milder cases. ${ }^{5}$ These rates are as high as for many forms of cancer. The morbidity caused by heart failure is reflected in the workloads of both the hospital service and general practice: there are 120000 hospital admissions per year ( $5 \%$ of all admissions to adult medical and geriatric wards), ${ }^{6-9}$ and it is estimated that for each hospital admission 14 consultations take place in general practice. ${ }^{3}$ The cost to the National Health Service is considerable: $£ 360$ million a year is spent on the management of heart failure, and $60 \%$ of this goes on hospital treatment alone. ${ }^{10}$ In several large trials angiotensinconverting enzyme (ACE) inhibitors have been shown to reduce mortality and also to improve symptoms and quality of life. ${ }^{41-13}$ These drugs are now licensed for use in general practice, where considerable marketing pressure is being applied.

In the United Kingdom most patients with heart failure are treated by general practitioners. ${ }^{3}$ An audit of six general practices in the Nottingham Health District found that only about half of the patients who had been prescribed loop diuretics fulfilled the diagnostic criteria for heart failure. ${ }^{14}$ Echocardiography had been performed in fewer than a third of cases in this survey and only $17 \%$ of patients with heart failure were receiving ACE inhibitors. This medication had been started by hospital physicians in nearly all cases. These observations and a recent study from Liverpool ${ }^{15}$ suggest that the diagnostic facilities necessary for optimal management of heart failure are not available to, or used by, general practitioners.

\section{Diagnosis of heart failure by general practitioners}

In common with other doctors, general practitioners suspect heart failure when patients present with dyspnoea or oedema. When these symptoms are combined with signs of a raised venous pressure or pulmonary congestion, clinical diagnosis is usually not difficult. None of these clinical features is specific to heart failure, however, and some of the important supporting evidence for the diagnosis (cardiac enlargement or the presence of a third heart sound) may be difficult to detect or may be masked by other diseases.

Coexisting conditions which cause symptoms that are similar to those of heart failure are more common in patients with pulmonary disease or in elderly patients. In such cases the clinical evidence available to the general practitioner is not sufficient to determine the extent to which heart failure may be causing the symptoms. Without echocardiography it is also difficult to determine the severity of impairment of ventricular function. Furthermore, general practitioners often see patients in the early stages of disease before the more florid features have developed.

The presence of a systolic murmur in a patient with heart failure invariably requires an echocardiographic and Doppler study to investigate the differential diagnoses of aortic stenosis, aortic sclerosis, and primary mitral regurgitation or secondary mitral regurgitation, and to determine whether or not the patient needs valve surgery. The diagnoses of mitral stenosis and pericardial disease can also prove difficult and both conditions may require surgery rather than medical treatment. The serious implications of a diagnosis of heart failure and the established benefits of appropriate medical and surgical treatment mean that all patients in whom the condition is suspected ${ }^{14}$ require an accurate diagnosis.

\section{Investigations available to the general practitioner}

The contributions of the chest $x$ ray and electrocardiogram to the diagnosis and assessment of severity of heart failure are limited. Haematological and biochemical investigations should be used to detect anaemia and thyroid dysfunction and to measure urea and electrolytes. None of these investigations establishes the diagnosis, however, and only rarely indicates a cause of heart failure. The recent discovery of the natriuretic peptides and the development of simple, cheap radioimmunossay techniques to measure their concentration in peripheral blood promises to be an important development. ${ }^{16}$ The presence of a raised concentration, particularly of the B-type natriuretic peptide, has been shown to provide a sensitive indication of left ventricular dysfunction. We do not know how useful this will be, but it could lead to a simple screening test that general practitioners might use to select patients who need further investigation or treatment. ${ }^{16}$

The most appropriate initial investigation for patients with heart failure is echocardiography combined with Doppler studies. This investigation will confirm left ventricular dysfunction as the cause of a patient's symptoms. In patients with symptoms of breathlessness who do not have heart failure, the echocardiogram may show normal ventricular function and thus avoid inappropriate treatment with ACE inhibitors. 
The echocardiographic examination should be performed with high resolution equipment, configured for cardiac use. It should show the left ventricular endocardium in detail and have appropriate analysis features to allow quantification of ventricular volumes and ejection fraction. A high quality videotape recorder should be used to store real-time (moving) images to allow future comparison and further advice/discussion, and for medico-legal purposes. The quality of the echocardiographic equipment should be high enough to permit detection and visualisation of common co-existing pathological features, such as left ventricular mural thrombus.

The echocardiographic equipment must also incorporate Doppler facilities, preferably including colour flow mapping. The haemodynamic information obtained from Doppler imaging, coupled with the anatomical and functional data from the cross sectional images, allows identification of structural causes of heart failure, quantification of the severity of valve lesions, and assessment of diastolic left ventricular function.

Access to quality echocardiographic equipment with appropriate facilities is, however, only one component of accurate cardiac ultrasound. The technique requires an operator with considerable expertise and experience to obtain and interpret the data. In 1994 the British Society of Echocardiography published recommendations for training and accreditation in echocardiography. ${ }^{17}$ The society strongly recommended that all echocardiographic studies should be performed by individuals with the "proficiency level accreditation". Appropriately trained and accredited cardiac technicians may perform the investigation, provided that the study report describes the echocardiographic findings but does not recommend or suggest any particular treatment.

The echocardiographic investigation of a patient with suspected heart failure may be technically difficult. The operator must have the experience and training to recognise that it is inappropriate to make measurements when image quality precludes quantification of left ventricular function. A qualitative evaluation of left ventricular function that will allow management decisions to be made may lie within the ability of an experienced echocardiographer. This makes operator skill and accreditation essential components of the echocardiographic services.

Currently there are too few trained operators to provide this important investigation to the patients who need it. General practitioners should not hesitate to refer appropriate patients so that local hospitals and purchasers are made aware of the need for high quality echocardiographic services.

\section{The future}

If general practitioners are to have increased access to echocardiographic investigation for patients with suspected heart failure, ${ }^{18} 19$ the equipment and staffing issues must be resolved. This should, in the first instance, be achieved by negotiating open access contracts with local hospital cardiac departments. Some of the funding for this may come from a concomitant reduction in unnecessary chest $x$ rays or electrocardiographs or both. We will save more if we avoid giving ACE inhibitors to patients who do not require them.

The alternative of transporting complex, delicate electronic equipment to large health centres or small hospitals without such facilities is ill advised. Wider access to a hospital based service seems to be the option that will provide the best quality equipment and staff.
The demand for echocardiographic investigations for assessment of all types of cardiac disease is increasing rapidly. A recent audit showed that the largest growth in demand was for the evaluation of left ventricular function after myocardial infarction in patients in whom heart failure is suspected. ${ }^{20}$ ACE inhibitors should not be prescribed by either general practitioners or hospital doctors without prior echocardiographic examination. In addition, considerably more general practitioners are requesting echocardiographic services. This increase in demand is both predictable and appropriate. Rigorous debate, careful planning, and education are needed to ensure that the quality of echocardiography and Doppler imaging is not compromised as the volume of investigations increases.

Whatever arrangements are agreed locally, patient care will improve only if a high quality echocardiography service is provided. We await the publication of a position paper from the British Cardiac Society on the subject of diagnosis and management of heart failure.

M C COLQUHOUN

General practitioner, Malvern COLIN WAINE

Director of Primary Care, Sunderland Health Commission M J MONAGHAN

President, British Society of Echocardiography A D STRUTHERS

Department of Clinical Pharmacology, Ninewells Hospital, Dundee
P G MILLS Associate editor, British Heart Journal

This joint editorial also appears in the October issue of the British fournal of General Practice.

Correspondence to: Dr P G Mills, British Heart fournal, 9 Fitzroy Square, London W1P 5AH.

1 Dargie HJ, McMurray J. Chronic heart failure: epidemiology, aetiology, pathophysiology and treatment. In: Rowlands DJ, ed. Recent advances in cardiology II. Edinburgh: Churchill Livingstone, 1992;73-114.

2 Parameshwar J, Shackell MM, Richardson A, Poole-William PA, Sutton GC. Prevalence of heart failure in three general practices in north west GC. Prevalence of heart failure in three
London. Br $\mathcal{G}$ Gen Pract 1992;42:287-9.

3 Wheeldon NM, MacDonald TM, Flucker CJ, McDermitt DG, Struthers $\mathrm{AD}$. An electrocardiographic study of chronic heart failure in the community. $Q \mathcal{F}$ Med 1993;86:17-23.

4 CONSENSUS trial group. Effects of enalapril on mortality in severe congestive heart failure. Results of the cooperative north Scandinavian enalapril survival study. $N$ Engl f Med 1987;316:1429-35.

5 McKee PA, Castelli WP, McNamara PM, Kannel WB. The natural history of congestive heart failure: the Framingham study. $N$ Engl $f$ Med 1971;285:1441-6.

6 Sutton GC. Epidemiological aspects of heart failure. Am Heart $\mathcal{f} 1990$; 120:1538-40.

7 McMurray J, Dargie HJ. Coronary heart disease. BMf 1991;303:1546.

8 McMurray J, Dargie HJ. Trends in hospitalisation for chronic heart failure in the United Kingdom. Eur Heart f 1992;13(suppl):350.

9 McMurray J, McDonagh T, Morrison CE, Dargie HJ. The growing problem of heart failure in Scottish hospitals. Br Heart $\mathfrak{f}$ 1993;69(suppl):P73.

10 McMurray J, Hart W. The economic impact of heart failure on the UK National Health Service. Eur Heart f 1993; 14(suppl): 133 .

11 Cohn JN, Arhibald DG, Ziesche S, et al. Effect of vasodilator therapy on mortality in chronic congestive heart failure. Results of a Veterans Affairs Administration cooperative study. $N$ Engl $f$ Med 1986;314: $1547-52$

12 Cohn JN, Johnson G, Ziesche S, et al. A comparison of enalapril with hydralazine-isosorbide dinitrate in the treatment of chronic congestive heart failure. N Engl F Med 1991;325:303-310.

13 The SOLVD investigators. Effects of enalapril on survival in patients with reduced left ventricular ejection fractions and congestive heart failure. $N$ Engl f Med 1991;325:293-302.

14 Clarke KW, Gray D, Hampton JR. Evidence of inadequate investigation and treatment of patients with heart failure. Br Heart f 1994;71:584-7.

15 Murphy JJ, Frain JP, Bossingham CM. 'Open access' to echocardiography for suspected heart failure: does it work? [abstr] $\mathrm{Br}$ Heart $\mathcal{f}_{1995}$; 73(suppl):P39.

16 Struthers $\mathrm{AD}$. Plasma concentrations of brain natriuretic peptide: will this new test reduce the need for cardiac investigations? $\mathrm{Br}$ Heart $\mathrm{f}$ 1993;70:397-8.

17 Education and Training Subcommittee of the British Society of Echocardiography. Training in echocardiography. Br Heart $\mathcal{f} 1994$; 71(April suppl):2-5.

18 Francis CM, Caruana L, Kearney $P$, et al. Open access echocardiography in management of heart failure in the community. BMF 1995;10:634-6. in management of heart failure in the community. BMF 1995;10:634-6. Mair FS, Crowley TS, Bundred PE. Audit of h

20 Gupta S, Why HJF, Jewitt DE, Monaghan MJ. Changing trends in an echocardiographic service: a five year retrospective audit [abstr]. $\mathrm{Br}$ Heart $₹$ 1995;73(suppl 2):41. 